Research Article

\title{
Effect of educational interventions on pharmacovigilance awareness among M.B.B.S. internee's in a tertiary care teaching hospital
}

\author{
Navneeth Selvan*, Revathy Saravanan, Sakthibalan M.
}

Department of Pharmacology, Sri Venkateshwaraa Medical College Hospital and Research Centre, Puducherry, India

Received: 18 November 2015 Accepted: 30 December 2015

\section{*Correspondence to:}

Dr. Navneeth Selvan,

Email: navneeth01@yahoo.co.in

Copyright: (C) the author(s), publisher and licensee Medip Academy. This is an open-access article distributed under the terms of the Creative Commons Attribution Non-Commercial License, which permits unrestricted non-commercial use, distribution, and reproduction in any medium, provided the original work is properly cited.

\begin{abstract}
Background: Spontaneous reporting of adverse drug reactions (ADRs) has played a major role in detection of previously unobserved ADRs. In spite of setting up ADR monitoring centres, only 6-10\% of all ADRs are reported which has been contributed to the lack of knowledge among healthcare professionals. This study was planned to address this aspect. To evaluate and compare the effect of educational intervention in enhancing the knowledge of MBBS internee's regarding pharmacovigilance.

Methods: A cross sectional, educational interventional observational study was conducted using two copies of a pretested validated questionnaire (pre \& post CME) with 17 questions among 130 MBBS internees. They were subjected to a Continuous Medical Education on pharmacovigilance. A hand's on training on ADR reporting was also conducted in which they were divided into 10 batches and asked to fill a Central Drugs Standard Control Organization Adverse Drug Reporting form on the case scenario given to them and forms were analyzed.

Results: Out of 130 internees, 114 (87.69\%) and 98 (75.38\%) had completely filled them. The overall awareness about pharmacovigilance increased from $62.50 \%$ to $82.25 \%$ ( $p<0.0001$ ). There was a statistically significant increase in mean value from $14.38 \pm 0.3020$ to $18.92 \pm 0.2860(\mathrm{p}<0.0001)$ on analyzing the knowledge scores. $90 \%$ of ADR forms revealed substantial errors, which were explained to the participants.

Conclusions: This study clearly shows that early sensitization through educational interventions at internship phase of M.B.B.S. will increase the number of ADRs being reported in our country.
\end{abstract}

Keywords: MBBS interns, Pharmacovigilance knowledge, Continuous medical education, Hands on training

\section{INTRODUCTION}

Pharmacovigilance, is derived from the Greek word; 'pharmakon', a drug or medicine, and from the Latin 'vigilans' watchful or careful, which was defined as 'all methods of assessment and prevention of adverse drug reactions'. It was later defined by the World Health Organization (WHO), as the "science and activities relating to the detection, assessment, understanding and prevention of the adverse effects (AE)", particularly long term and short term side effects of medicines or any other drug related problems. ${ }^{1}$

Adverse drug reactions (ADRs) are one of the leading causes of morbidity and mortality. Previous studies have revealed that around $2.9-5.6 \%$ of all hospital admissions are due to ADRs and as many as $35 \%$ of hospitalized patients experience an ADR during their period of hospitalization. ${ }^{2}$ Spontaneous reporting of ADRs is one of the basic methods for post-marketing surveillance and is a method to generate signals of unrecognized ADRs. ${ }^{3} \mathrm{It}$ remains the cornerstone of pharmacovigilance. ${ }^{4}$ To transform the concept of pharmacovigilance in to practice, ADR monitoring centres (AMCs) have been set up across the country under Pharmacovigilance Programme of India (PvPI) to enhance and ensure the safety of patients. ${ }^{5}$

The pharmacovigilance programme in India started in the year 2010 with a mission to safeguard the health of the Indian population by ensuring that the benefit of using medicine outweighs the risks associated with its use. ${ }^{6}$ In spite of the best efforts, still the reporting of serious ADRs rarely exceeds $10 \% .^{4}$ This high rate of underreporting can delay detection of serious ADRs \& have a major negative impact on the public health. Thus, 
underreporting still remains a major obstacle in the complete success of the pharmacovigilance program. ${ }^{7}$ Based upon various studies, the increased rate of underreporting has been contributed to be due to lack of awareness about ADR reporting which in turn has been attributed to time constraints, misconceptions about spontaneous reporting and bureaucratic reporting procedures, lack of information on how to report and a lack of availability of report forms, and physicians' attitudes to ADRs. ${ }^{8}$ It is to be noted that sadly, majority of the physicians in India are not even aware of The pharmacovigilance programme of India. ${ }^{9}$ Internship phase of training during MBBS course is a crucial period wherein a graduate is expected to conduct actual practice of medical and health care and acquire skills under supervision so that he/she may become capable of functioning independently. ${ }^{10}$

This transitional phase of Internship is vital in the life of a physician during which he/she is subjected to various practical scenarios resulting in maximal learning. Prior proper sensitization of Physicians about ADR recognition and reporting and PVPi during the phase of internship, before foraying into independent medical practice, will help us increase the number of ADRs being reported which also will reduce unnecessary ADR signals. Educational interventions in the form of lecture and hands on practical training are some of the methods which have been proved to be effective in sensitization and awareness generation. The present study encompasses all the above said points in an effective manner.

\section{Aim}

To evaluate and compare the effect of educational interventions in enhancing the knowledge of MBBS internee's regarding pharmacovigilance.

\section{Objectives}

- To assess the level of knowledge related to Pharmacovigilance among MBBS internee's before and after educational interventions.

- To compare the effect of educational interventions in enhancing their knowledge.

\section{METHODS}

A cross sectional educational interventional study was done among 130 MBBS internees of a tertiary care teaching hospital in Puducherry by administering a pretested validated questionnaire containing 17 questions in standard English on July 2015 after obtaining written informed consent with the permission of Institutional Research and Ethics committees. Before the start of the educational intervention, pre evaluation questionnaires were distributed among individual internees. A time of 10 minutes was given to the internees to fill the pre evaluation questionnaire, before the educational intervention. All the internee's were subjected to educational intervention in the form of continuous medical education on pharmacovigilance which consisted of a lecture followed by hand's on training on ADR reporting. The internee's were divided into 10 batches. Each batch was given a clinical scenario and a Central Drugs Standard Control Organization Adverse Drug Reporting form. Within a stipulated time of 10 minutes, they were asked to fill in the ADR form accordingly. After the educational interventions, they were asked to answer the post evaluation questionnaire in 10 minutes.

Only completely filled questionnaires were taken up for analysis. Each correct response was given a score of 1 . Except 7 and 9 which has a maximum score of 4 each. The total score is 23 . The knowledge score was graded as follows:

- Low score : 0- 12

- Moderate score: $13-17$

- High score: $18-23$

The answers of pre and post evaluation questionnaires were analyzed and compared using paired test for statistical significance of $\mathrm{p}$ value $<0.0001$. The filled ADR forms were also analyzed for their completeness \&errors. The continuous variables were expressed by means and standard deviations.

\section{RESULTS}

Out of 130 internees, $114(87.69 \%)$ and $98(75.38 \%)$ gave complete answers to the pre and post intervention questionnaire respectively. There was a statistically significant increase in mean value \pm standard error from $14.38 \pm 0.3020$ to $18.92 \pm 0.2860(\mathrm{p}<0.0001)$ on comparison of both the questionnaires (Table 2). The overall knowledge of the internees were also scored and analyzed as given above. It was found that the low score substantially decreased from $30.70 \%$ to $4.08 \%$ whereas the moderate and high scores increased from $55.26 \%$ to $21.42 \%$ and from $11.11 \%$ to $74.48 \%$ respectively after the educational CME (Figure 1). Individual responses to each question before and after the educational interventions were also compared. The awareness of the meaning of pharmacovigilance increased from $82.45 \%$ to $94.89 \%$. The percentage of students who understood the difference between an adverse drug reaction and adverse drug event increased from $85.96 \%$ to $92.85 \%$. There was a $12.17 \%$ increase in awareness, that the ADR is not being related only to its active ingredient, which might also be caused by solvents or excipients used or due to contaminants during manufacturing. The knowledge of type B ADR and voluntary reporting systems increased almost double fold from $22.80 \%$ to $48.97 \%$ and from $31.79 \%$ to $78.82 \%$ respectively. 


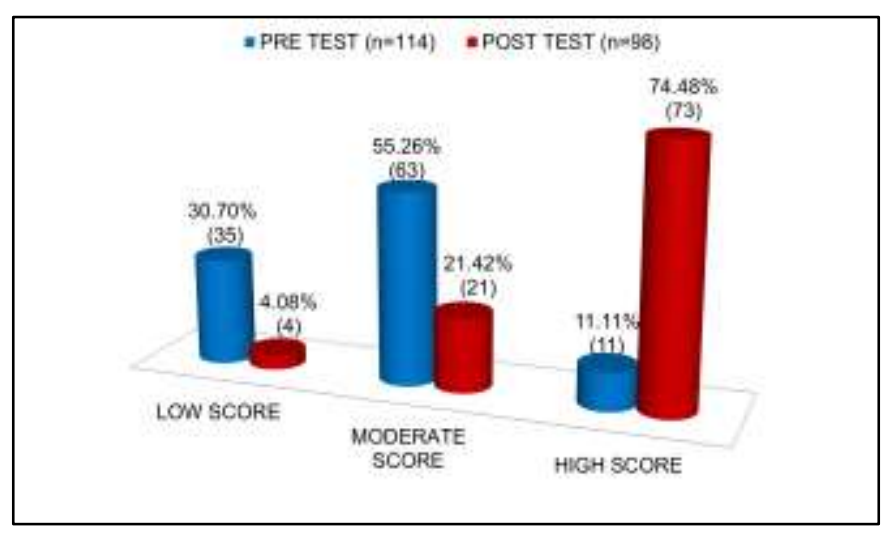

Figure 1: Knowledge score among internees.

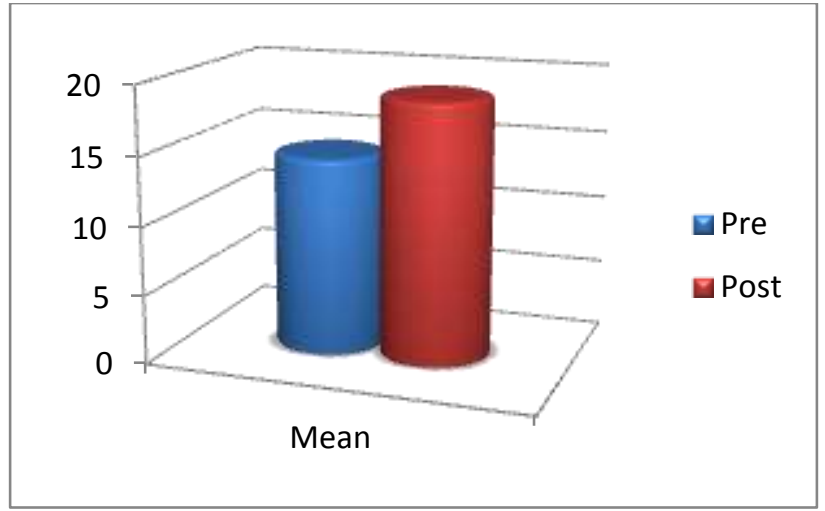

Figure 2: Mean value of pre and post evaluation questionnaire.

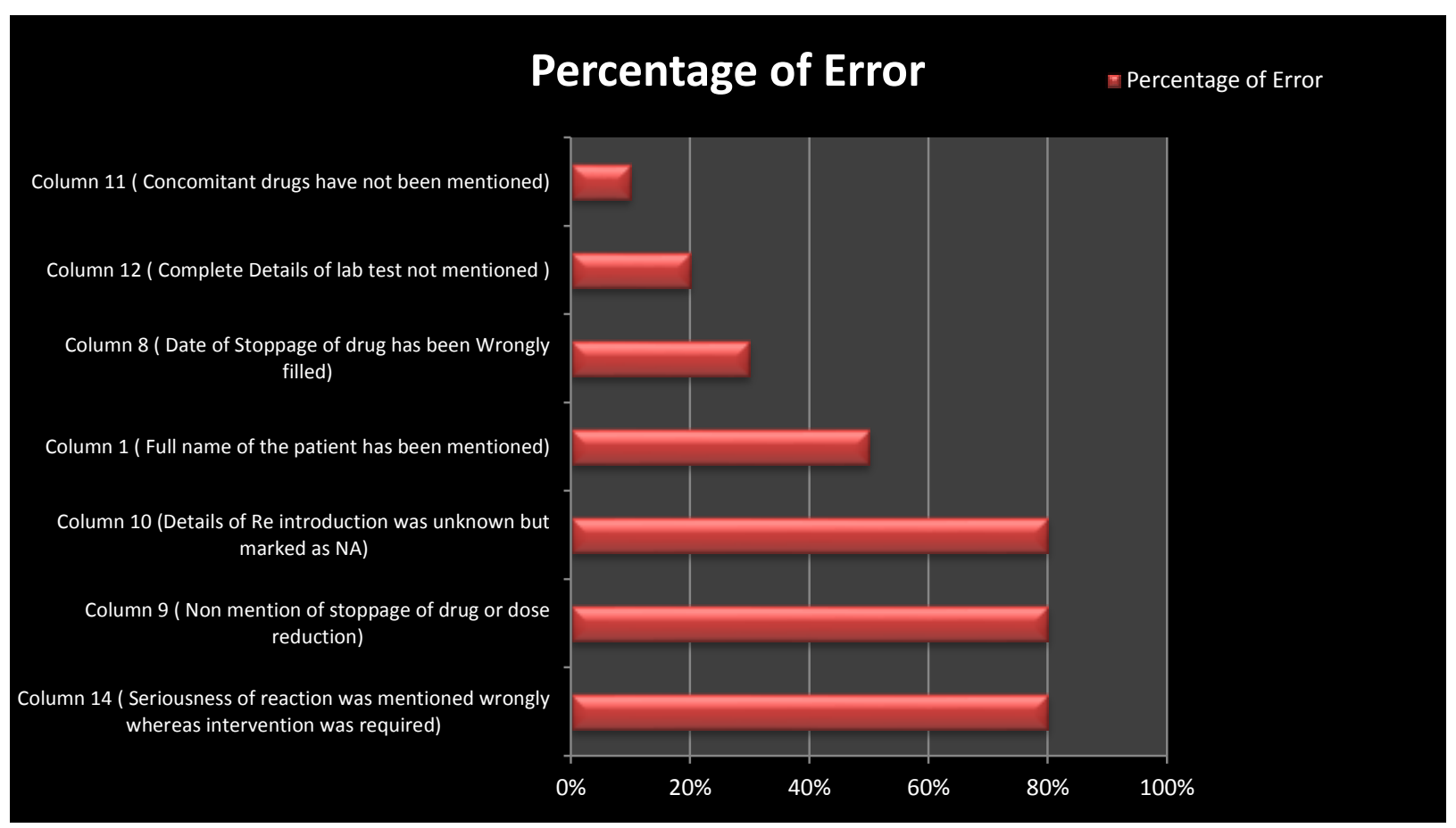

Figure 3: Percentage of errors in CDSCO ADR forms.

The correct response of Internees who wrote the full expansion of CDSCO increased by a significant $34.16 \%$. Thus the overall awareness and knowledge of pharmacovigilance increased from $62.50 \%$ to $82.25 \%$ (Table 1). On completion of the hands' on training on ADR reporting, 9 (90\%) out of 10 batches filled the ADR forms which were analysed. Though $90 \%$ of internee's filled the ADR forms, several wrong responses were noted on analysis. $80 \%$ of the internees had wrongly filled columns 14, 10 and 9 pertaining to seriousness of the reaction as hypersensitivity reaction or disability, reintroduction of the drug as not applicable for reintroduction even when it was unknown and no mention of whether drug stoppage or dose reduction respectively were observed. $30 \%$ of the internees had wrongly filled the date of stoppage of drug in column 8 . $20 \%$ and $10 \%$ of the internee's had not mentioned the complete details of lab test in column 12 and details of concomitant drugs in column 11 respectively. Some errors were also noted in column 1 wherein full name of the patient was mentioned (Figure 3). 


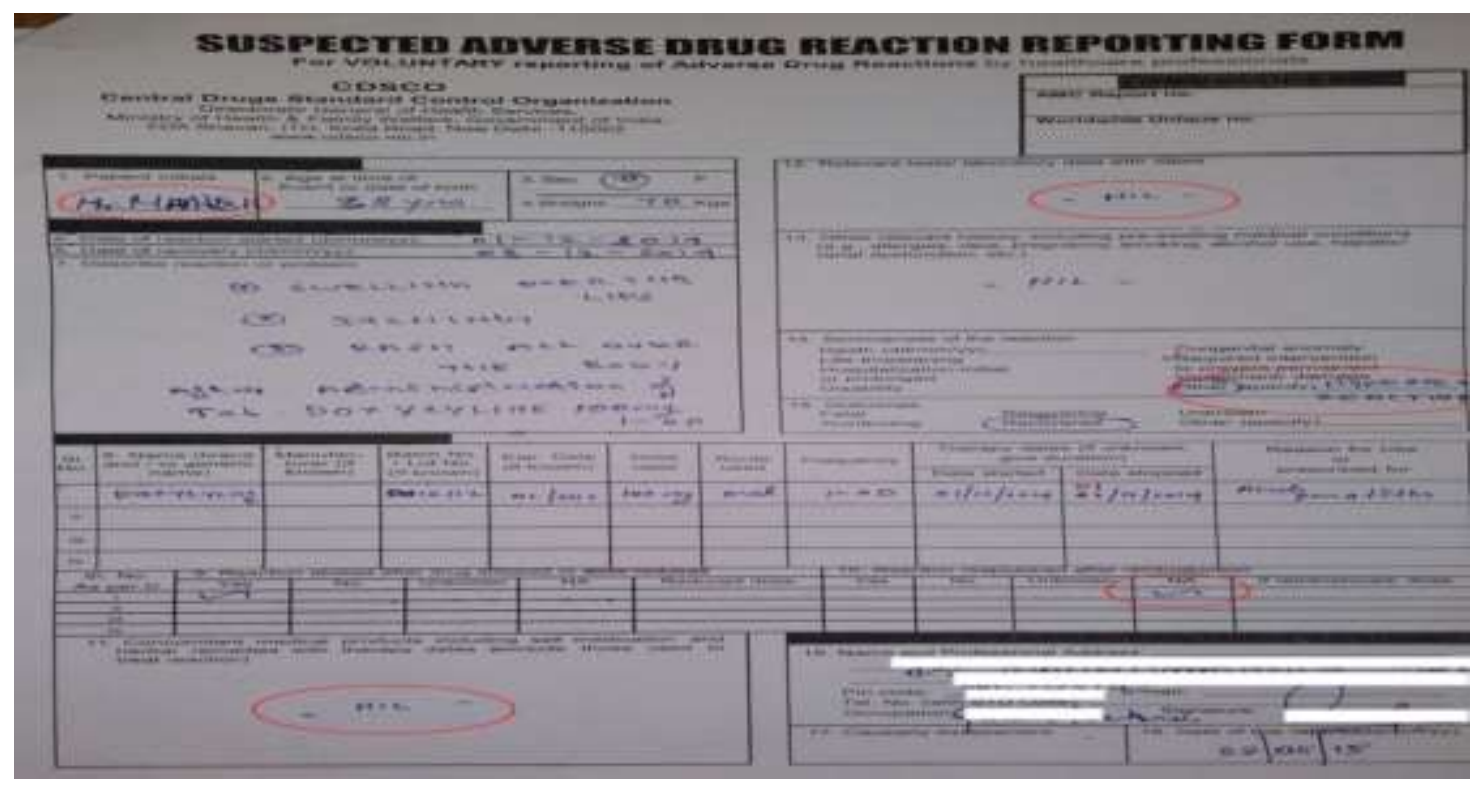

Figure 4: Sample analysed form for errors.

Table 1: Comparison of correct response of pre and post educational intervention questionnaire.

\begin{tabular}{|c|c|c|}
\hline Question & $\begin{array}{l}\text { Correct pre } \\
\text { educational } \\
\text { intervention } \\
\text { response } \\
(n=114)\end{array}$ & $\begin{array}{l}\text { Correct post } \\
\text { educational } \\
\text { intervention } \\
\text { response } \\
(n=98)\end{array}$ \\
\hline What is Pharmacovigilance & $82.45 \%$ & $94.89 \%$ \\
\hline Adverse drug reaction ( ADR) \& Adverse Event ( $\mathrm{AE}$ ) are the same & $85.96 \%$ & $92.85 \%$ \\
\hline Cause for ADR is always due to its active ingredient only & $74.56 \%$ & $86.73 \%$ \\
\hline $\begin{array}{l}\text { ADE is any untoward medical occurrence in a patient administered } \\
\text { pharmaceutical product which does not necessarily have a casual } \\
\text { relationship with the treatment }\end{array}$ & $64.03 \%$ & $83.67 \%$ \\
\hline What is type B ADR & $22.80 \%$ & $48.97 \%$ \\
\hline ADR is considered even when it occurs at therapeutic dose & $62.28 \%$ & $84.69 \%$ \\
\hline Causes for withdrawal of drugs & $81.57 \%$ & $94.13 \%$ \\
\hline Who can report ADR & $57.89 \%$ & $80.61 \%$ \\
\hline What are the voluntary reporting systems & $31.79 \%$ & $78.82 \%$ \\
\hline Full expansion of CDSCO & $60.52 \%$ & $94.68 \%$ \\
\hline Phase of post marketing surveillance & $60.52 \%$ & $74.48 \%$ \\
\hline $\begin{array}{l}\text { Time to report any serious adverse events by pharmaceutical industries } \\
\text { during their clinical trial to DGCI's office }\end{array}$ & $79.82 \%$ & $89.79 \%$ \\
\hline Time sequence based on which the causality assessment is done & $69.29 \%$ & $77.55 \%$ \\
\hline Constituents of a valid ADR report & $71.92 \%$ & $82.65 \%$ \\
\hline Who does the causality assessment & $38.59 \%$ & $53.06 \%$ \\
\hline $\begin{array}{l}\text { Is pharmacovigilance unit an essential requirement in all medical } \\
\text { institution with hospital services }\end{array}$ & $89.47 \%$ & $93.87 \%$ \\
\hline After ADR confirmation due to a drug, which will not be initiated & $64.03 \%$ & $65.30 \%$ \\
\hline
\end{tabular}


Table 2: Mean and standard error of pre and post evaluation questionnaire.

\begin{tabular}{|llllll|}
\hline Test & Mean \pm se & Maximum & Minimum & t value & p value \\
\hline $\begin{array}{l}\text { Pre test } \\
(\mathbf{n = 1 1 4})\end{array}$ & $14.38 \pm 0.3020$ & 22.00 & 7.00 & 10.74 & $<0.0001$ \\
\hline $\begin{array}{l}\text { Post test } \\
(\mathbf{n = 9 8})\end{array}$ & $18.92 \pm 0.2860$ & 23.00 & 11.00 & & \\
\hline
\end{tabular}

\section{DISCUSSION}

To the best of our knowledge this is the first educational interventional study on pharmacovigilance conducted among MBBS internees. In this study the knowledge of internee's regarding pharmacovigilance showed marked increase after subjecting to educational interventions similar to the study done by Jha $\mathrm{N}$ et al among health care professionals. ${ }^{11}$ It is important for healthcare providers to know how and where to report an ADR. The present study showed significant increase in knowledge of types of ADR and reporting person of ADR from $22.80 \%$ to $48.97 \%$ and $57.89 \%$ to $80.61 \%$ respectively. A study done by Khan et al in 2013 showed that there was a significant lack of awareness among doctors in a teaching hospital in India about the existing pharmacovigilance program of India. ${ }^{12}$ The cross sectional study done by us also unfolds the lack of awareness of voluntary reporting systems among the internees, and it has been addressed by the current study. The observed significant increase in the knowledge of voluntary reporting system from $31.79 \%$ to $78.82 \%$ by us has highlighted the influence and importance of such awareness enhancing programmes. We know that ADR reporting has emerged as a cornerstone in pharmacovigilance. $80 \%$ of the internee forms that were analyzed had wrongly filled column 14 indicating the seriousness of reaction as hypersensitivity or disability because of the dilemma whether the active ingredient of the drug caused hypersensitivity reaction or disability. Whereas according to the clinical scenario given to them, the patient suffered no permanent disability or prolonged hospitalization whereas the scenario has only warranted an intervention for the reaction. An equal number of internees had also filled column 10 as not applicable. The filling of this column as not applicable shows insufficient knowledge of internees about the basic information seeked. This mainly helps to clarify whether the ADR noted is due to the drug or not. When in doubt this is done by observing the disappearance of ADR on stopping the drug (dechallenge) and reappearance on reintroduction (rechallange) which should not be attempted when the ADR is known to be due to the administered drug. This will help to quantify the causal relationship between the suspected medicine and the reaction observed. Hence it should be written as, "not done" rather than "not applicable". So it is highly essential to be aware of possible ADRs at least for commonly used medicines. Otherwise making bed side references available will help to recognize and relate them. This correlates with the equal number of internees who did not respond to the column 9 which states whether the reaction abated after drug stoppage or dose reduction which is going to further confirm the status of the suspected drug. Otherwise the drug may be continued or the drug which may not be the actual cause may likely to be stopped in the fear of further reaction. As these columns closely intertwine with each other, in depth understanding of each of the drug given in the clinical scenario is necessary. The date of stoppage of drug plays a vital role in identification of the adverse drug reaction, but that was even wrongly filled by $30 \%$ of the internees. Another important aspect is concomitant drugs administered to be mentioned in column 11. Concomitant drugs are one of the major causes of adverse drug reactions these days. When more than one drug is given together it can tend to be irrational or interact with each other if not properly selected. Thus the knowledge of concomitant drugs will help us to rule out any drug interactions being the cause for such ADRs which can be prevented in future by proper selection of drugs and by avoiding irrational prescriptions. This column was also not filled by $10 \%$ of the internees whereas a double fold of internees. i.e $20 \%$ of them have not filled in the complete details of laboratory tests in column 12, which would give a clear idea of the condition of the patient for which the drug in question was given along with justification for the same. Our study has confirmed that theoretical expertise alone will not be enough for ADR reporting to be effective, as lack of understanding in filling up the ADR form will not be beneficial or it may even lead to confusion and uncertainty. This aspect has been very well evidenced in our study. Hence, similar practical exercises with feedback involving all health care providers like physicians, nurses and pharmacists etc. will improve the reporting standards resulting in standardized safe and effective therapeutic outcome.

\section{Strengths and limitations of the study}

This study had a major advantage of combining two forms of educational interventions, a theoretical intervention in the form of a lecture on pharmacovigilance and another practical hands-on training on adverse drug reaction reporting. This unique aspect of this study makes it to stand apart from rest of the studies.

The only limitation to this study was the number of participants and focused group of participants. The results may not be generalized and extrapolated to all MBBS 
internees. This type of awareness creating programs can be extended to all the partners in the pharmacovigilance programme to be more effective.

\section{CONCLUSION}

The definitive positive impact of CME and practical exercises with feedback on pharmacovigilance has been evidenced in our study. Intensive short course pharmacovigilance training in the pivotal MBBS internship phase will help us to sensitize them towards the importance of ADR reporting prior to foraying as a full time physician resulting in the success of the pharmacovigilance program of India. Inclusion of such educational interventions in the MCI curriculum can be suggested.

\section{ACKNOWLEDGEMENTS}

We would like to place our acknowledgement to the faculties of department of Pharmacology, and most importantly the MBBS internees and the management of Sri Venkateshwaraa Medical College Hospital and Research Centre, Puducherry for their voluntary participation and co-operation.

Funding: No funding sources Conflict of interest: None declared

Ethical approval: Study protocol was approved by Institutional Animal Ethics Committee.

\section{REFERENCES}

1. World Health Organization. Safety of medicines. A guide to detecting and reporting adverse drug reactions. Why health professionals need to take action. Geneva World Health Organization. 2002.

2. BaniasadiSh, Fahimi F, Shalviri G. Developing an adverse drug reaction reporting system at a teaching hospital. Basic Clin Pharmacol Toxicol. 2008;102:408-11.

3. Ekman E, Backstrom M. Attitudes among hospital physicians to the reporting of adverse drug reactions in Sweden. Eur J Clin Pharmacol. 2009;65:43-6.
4. Green CF, Mottram DR, Rowe PH, Pirmohamed M. Attitudes and knowledge of hospital pharmacists to adverse drug reaction reporting. $\mathrm{Br} \quad \mathrm{J}$ Clin Pharmacol. 2001;51:81-6.

5. Pharmacovigilance programme of India 2010. CDSCO, Ministry of Health and Family Welfare, Government of India. 2010. Available at http://cdsco.nic.in/pharmacovigilance.htm. Accessed on 2015 June 23.

6. http://www.ipc.gov.in/PvPI/pv_about.html. Accessed on 2015 October 25.

7. Lopez-Gonzalez E, Herdeiro MT, Figueiras A. Determinants of underreporting of adverse drug reactions: a systematic review. Drug Saf. 2009;32:19-31.

8. Elnour AA, Ahmed AD, Yousif MA, Shehab A. Awareness and reporting of adverse drug reactions among health care professionals in Sudan. Jt Comm J Qual Patient Saf. 2009;35(6):324-9.

9. Tandon VR, Mahajan V, Khajuria V, Gillani Z. Under-reporting of adverse drug reactions: A challenge for pharmacovigilance in India. Indian $\mathbf{J}$ Pharmacol. 2015;47:65-71.

10. http://www.informationmbbs.in/2010/11/mbbsinternship-in-india.html. Accessed on 2015 October 25.

11. Jha N, Rathore DS, Rathore DS, Shankar PR, Gyawali S, Alshakka M, Bhandary S. An educational intervention's effect on healthcare professionals' attitudes towards pharmacovigilance. AMJ. 2014;7(12):478-89.

12. Khan SA, Goyal C, Chandel N, Rafi M. Knowledge, attitudes, and practice of doctors to adverse drug reaction reporting in a teaching hospital in India: An observational study. J Nat SciBiol Med. 2013;4(1):191-6.

Cite this article as: Selvan N, Saravanan R, Sakthibalan M. Effect of educational interventions on pharmacovigilance awareness among M.B.B.S. internee's in a tertiary care teaching hospital. Int J Basic Clin Pharmacol 2016;5:149-54. 